\title{
PRÉSENTATION DE LAURENT MAUVIGNIER
}

RELIEF 6 (2), 2012 - ISSN: 1873-5045. P 13-14

http://www.revue-relief.org

URN:NBN:NL:UI:10-1-113719

Igitur publishing

(C) The author keeps the copyright of this article

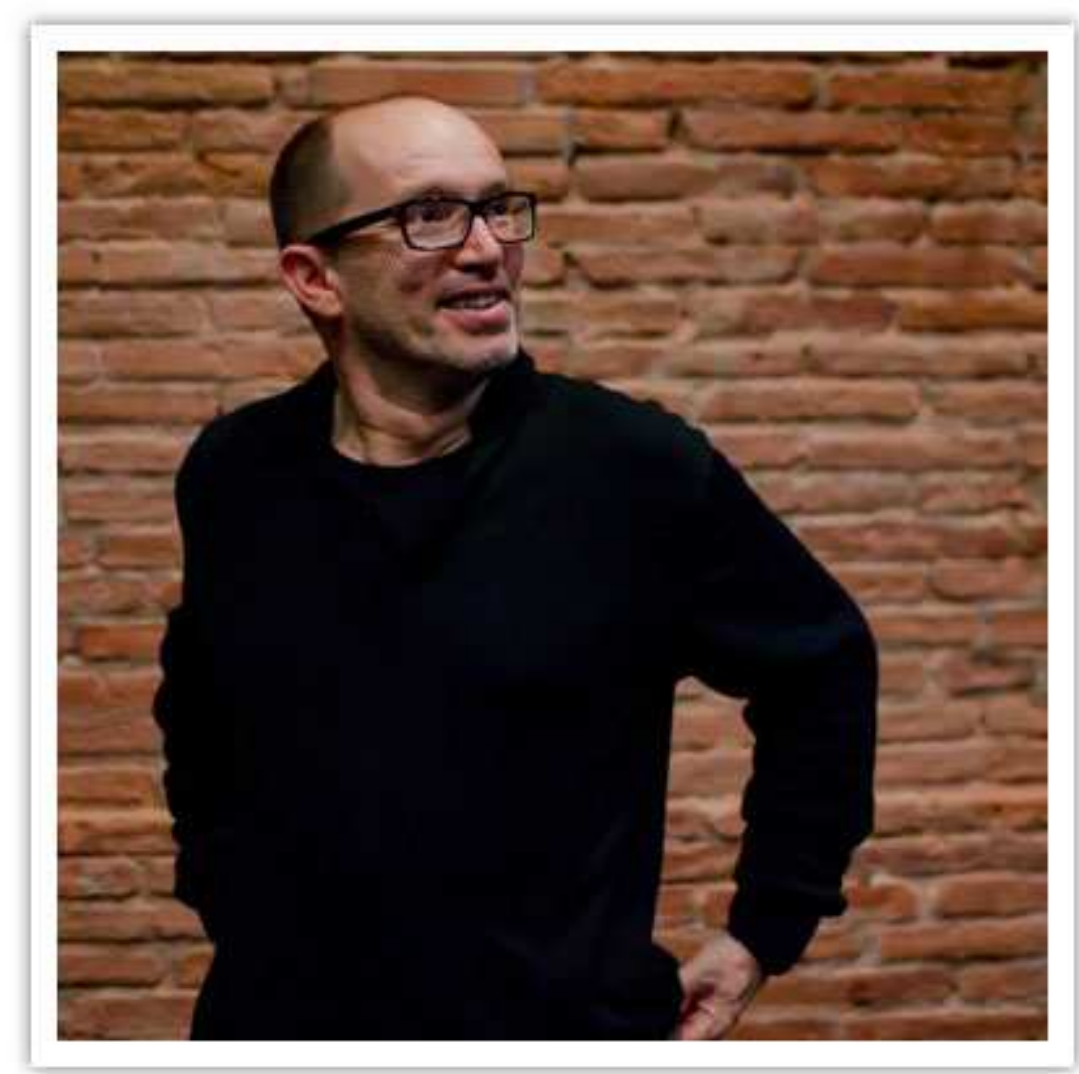

Photo provenant du site http://www.laurent-mauvignier.net/

\section{Quelques réponses au Questionnaire Proust}

\begin{tabular}{|l|l|}
\hline \multicolumn{1}{|c|}{ Questions } & \multicolumn{1}{|c|}{ Vos réponses } \\
\hline 1. Le principal trait de mon caractère? & $\begin{array}{l}\text { La détermination et le sentiment } \\
\text { de la solitude, à égale prégnance : } \\
\text { l'un me servant à ne pas } \\
\text { succomber à l'autre. }\end{array}$ \\
\hline
\end{tabular}




\begin{tabular}{|l|l|}
$\begin{array}{l}\text { 2. La qualité que je désire chez un } \\
\text { homme? }\end{array}$ & $\begin{array}{l}\text { La qualité que je PREFERE chez } \\
\text { un homme : la fragilité dans la } \\
\text { force. }\end{array}$ \\
\hline $\begin{array}{l}\text { 3. La qualité que je préfère chez une } \\
\text { femme? }\end{array}$ & $\begin{array}{l}\text { La qualité que je DESIRE chez une } \\
\text { femme : la force dans la fragilité. }\end{array}$ \\
\hline $\begin{array}{l}\text { 4. Ce que j'apprécie le plus chez mes } \\
\text { amis? }\end{array}$ & $\begin{array}{l}\text { Ma tendance - jusqu'à une } \\
\text { certaine intransigeance - à exiger } \\
\text { des autres qu'ils soient à la hauteur } \\
\text { de ce qu'ils pourraient être. }\end{array}$ \\
\hline Mon principal défaut? & $\begin{array}{l}\text { Marcher dans les villes jusqu'à } \\
\text { l'épuisement, me laisser croire que } \\
\text { je vis dans cette ville, dans cette } \\
\text { rue, regarder les gens, à l'occasion } \\
\text { les suivre de loin, les voir entrer } \\
\text { dans des immeubles, imaginer s'ils } \\
\text { vont chez eux, chez un ami, un } \\
\text { amour, leur médecin. Agrandir les } \\
\text { silhouettes en leur imaginant une } \\
\text { vie, une histoire, un devenir. }\end{array}$ \\
\hline Mon occupation préférée?
\end{tabular}

Laurent Mauvignier est né à Tours en 1967. Prix Wepler 2000 et Prix Livre Inter 2001 pour Apprendre à finir. Prix du roman Fnac 2006 pour Dans la foule.

Bibliographie (extrait) :

* Loin d'eux, roman (Minuit, 1999 et « double » n²0, 2002).

* Apprendre à finir, roman (Minuit, 2000 et « double », 2006).

* Ceux d'à côté, roman (Minuit, 2002).

* Seuls, roman (Minuit, 2004 et « double » n²7, 2004).

* Le Lien, roman (Minuit, 2005).

* Dans la foule, roman (Minuit, 2006).

* Des hommes, roman (Minuit, 2009).

* Ce que j'appelle oubli, roman (Minuit, 2011).

* Tout mon amour, théâtre (Minuit, 2012).

Voir

http://www.leseditionsdeminuit.fr/f/index.php?sp=livAut\&auteur_id=1433 